\title{
CORRIGENDUM
}

\section{Calhm2 governs astrocytic ATP releasing in the development of depression-like behaviors}

M Jun, Q Xiaolong, Y Chaojuan, P Ruiyuan, W Shukun, W Junbing, H Li, C Hong, C Jinbo, W Rong, L Yajin, M Lanqun, W Fengchao, W Zhiying, A Jianxiong, W Yun, Z Xia, Z Chen and Y Zengqiang

Molecular Psychiatry (2018) 23, 1091; doi:10.1038/mp.2017.254; published online 9 January 2018

Correction to: Molecular Psychiatry (2017) 22, e-pub ahead of print 28 November 2017; doi:10.1038/mp.2017.229

The authors' names were presented incorrectly. The names are presented correctly below.
J Ma, X Qi, C Yang, R Pan, S Wang, J Wu, L Huang, H Chen, J Cheng, $\mathrm{R}$ Wu, Y Liao, L Mao, FC Wang, Z Wu, JX An, Y Wang, X Zhang, C Zhang and Z Yuan 